\title{
Effects of methylmercury on electric organ discharges in the weak electric fish Gymnotus sylvius
}

\author{
Fernanda Dias de Moraes ${ }^{1}$, Caio Maximino ${ }^{2}$, Fábio Alves de Carvalho ${ }^{3}$, Alceu Ferreira Alves ${ }^{4}$, \\ Hugo Medeiros Garrido de Paula ${ }^{4, \dagger}$, and Amauri Gouveia $\mathrm{Jr}^{2}$ \\ 1- Universidade Federal de São Carlos, São Carlos, SP, Brazil \\ 2-Universidade Federal do Pará, Belém, PA, Brazil \\ 3-Universidade de São Paulo, Butantã, SP, Brazil \\ 4- Universidade Estadual Paulista, Bauru, SP, Brazil \\ $\uparrow$ Deceased
}

\begin{abstract}
Methylmercury $(\mathrm{MeHg})$ is present in the environment because of natural and anthropogenic causes. MeHg can reach the central nervous system (CNS) and cause neurological damage in humans and animals. Electric organ discharges (EODs) in the weak electric fish Gymnotus sylvius are produced by the electric organ and modulated by the CNS. These discharges are used for electrolocation and communication. The purpose of the present study was to investigate the effects of dietary MeHg exposure on EOD rate in G. sylvius. An oscilloscope was used to record the EOD rate. Two treatments were investigated: chronic $\mathrm{MeHg}$ administration $(4 \mu \mathrm{g} / \mathrm{kg} \mathrm{MeHg}$ every 2 days, with a total of nine dietary exposures to $\mathrm{MeHg}$ ) and acute $\mathrm{MeHg}$ administration (a single dose of $20 \mu \mathrm{g} / \mathrm{kg} \mathrm{MeHg}$ ). The control data for both treatments were collected every 2 days for 18 days, with a total of nine sessions (day 1 until day 18). Data of fish exposed to MeHg were collected every 2 days, totaling nine sessions (day 19 until day 36). Chronic treatment significantly increased the EOD rate in G. sylvius $(p<.05)$, especially with the final treatment (day 32 until day 36). Acute treatment resulted in an initial increase in the EOD rate, which was maintained midway through the experiment (day 26 until day $30 ; p<.05$ ). The present study provides the first insights into the effects of MeHg on EODs in weak electric fish. The EOD rate is a novel response of the fish to MeHg administration. Keywords: electric organ discharge (EOD), methylmercury, electroreception, novel response.
\end{abstract}

Received 16 October 2012; received in revised form 4 May 2013; accepted 18 May 2013. Available online 27 June 2013.

\section{Introduction}

Mercury is present in the environment because of natural and anthropogenic events. Methylmercury $(\mathrm{MeHg})$ is an organic form of mercury and the most toxic mercurial compound. The extensive use of $\mathrm{MeHg}$

Fernanda Dias de Moraes, Universidade Federal de São Carlos, Departamento de Genética e Evolução, São Carlos, São Paulo, Brazil. Amauri Gouveia Jr. and Caio Maximino, Universidade Federal do Pará, Núcleo de Teoria e Pesquisa do Comportamento, Belém, Pará, Brazil. Fábio Alves de Carvalho, Universidade de São Paulo, Instituto de Psicologia, Butantã, São Paulo, Brazil. Alceu Ferreira Alves, Universidade Estadual Paulista, Departamento de Engenharia Elétrica, Bauru, São Paulo, Brazil. Hugo Medeiros Garrido de Paula, Universidade Estadual Paulista, Departamento de Ciências Biológicas, Bauru, São Paulo, Brazil. Correspondence regarding this article should be directed to: Fernanda Dias de Moraes, Universidade Federal de São Carlos, Departamento de Genética e Evolução, Rod. Washington Luiz Km 235, São Carlos, São Paulo, CEP 13565-905, Brazil. Phone: +55 016 33518376. Fax: +55 016 33518377. E-mail: fer.diasmoraes@ gmail.com in gold mining leads to aquatic pollution, which has been documented in Amazonian rivers (Akagi et al., 1995; Rabitto et al., 2011). MeHg is hazardous to wildlife and humans who consume contaminated fish. When $\mathrm{MeHg}$ reaches the aquatic environment, it can be incorporated into the food chain when absorbed by the gills or digestive tract of aquatic organisms (Pinheiro et al., 2000; Wang, Wong, \& Wang, 2010; Dutton, \& Fischer, 2011).

$\mathrm{MeHg}$ especially affects the nervous system, leading to recognized neurological diseases in humans and animals (Vilagi, Doczi, \& Banczerowski-Pelyhe, 2000; Mieiro, Pereira, Duarte, \& Pacheco, 2011). The mechanisms of $\mathrm{MeHg}$ neurotoxicity are still under investigation, but $\mathrm{MeHg}$ is known to disrupt protein synthesis by reacting with sulfhydryl (-SH) groups in enzymes and other small molecules such as glutathione (GSH; Bondy \& Agrawal, 1980; Castoldi, Coccini, Ceccatelli, \& Manzo, 2001; Farina, Rocha, Aschner, 2011). Alterations in GSH homeostasis can induce oxidative stress (Farina et al., 2011), leading to the oxidation of lipids, proteins, and DNA in mammals and 
fish (Grotto et al., 2011; Vicari, Ferraro, Ramsdorf, Mela, Ribeiro, \& Cestari, 2012). Glutamate dyshomeostasis in the central nervous system (CNS) is another neurotoxic effect of MeHg (Aschner, Yao, Allen, \& Tan, 2000; Farina et al., 2011). MeHg inhibits astrocytic glutamate uptake and increases glutamate release, leading to elevated extracellular glutamate levels and MeHginduced excitotoxicity (Allen, Shanker, Tan, \& Aschner, 2002; Aschner et al., 2000; Farina et al., 2011). Glutamate is a major excitatory neurotransmitter in the CNS, and extracellular glutamate accumulation can provoke overactivation of $N$-methyl-D-aspartate (NMDA)-type glutamate receptors, leading to an increase in $\mathrm{Na}^{2+}$ and $\mathrm{Ca}^{2+}$ influx into neurons and consequently the induction of cell death pathways (Farina et al., 2011).

Neurological effects associated with sensorial and behavioral disturbances in fish have been observed with $\mathrm{MeHg}$ accumulation in the nervous system (Baatrup, 1991; Hawryshyn \& Mackay, 1979). The species Fundulus heteroclitus was exposed to $\mathrm{MeHg}$ and presented impairments in prey-capture behavior (Smith \& Weis, 1997). Such an effect was attributed to reduced serotonin levels, which was also seen in Oreochromis niloticus when exposed to the mercurial compound (Tsai, Jang, \& Wang, 1995). Schooling behavior and delayed spawning were observed in Notemigonus crysoteucas (Webber \& Haines, 2003) and Pimephales promelas (Hammerschmidt, Sandheinrich, Wiener, \& Rada, 2002), respectively, when they were contaminated with $\mathrm{MeHg}$. MeHg also induces oxidative stress, alterations in serotonin levels, and anxiogenic-like behavior in Danio rerio (Maximino et al., 2011). The olfactory and visual systems in fish are also vulnerable to mercurial compounds (Baatrup, 1991; Tanan et al., 2006). Reports also indicate that $\mathrm{MeHg}$ intoxication affects neurophysiology and sensory-motor coordination in fish.

Gymnotus sylvius is a weak electric fish that emits low-voltage electric pulses at a discharge rate of 20-70 Hz. The external morphology of this species is very similar to $G$. carapo, but it is biogeographically more restricted to central rivers in Brazil. In gymnotids, electric organ discharges (EODs) are used for electrolocation and communication (Hopkins, 1988; Stopa \& Hoshino, 1999), which determines reproductive and nonreproductive interactions. The EOD is produced by electric organs situated along the lateral line, and the CNS is highly involved in the control of electric activity.

Despite the increased studies on the effects of $\mathrm{MeHg}$ in aquatic animals, no data are available about the effects of $\mathrm{MeHg}$ on electric activity in fish. The aim of the present study was to investigate the effects of dietary exposure to $\mathrm{MeHg}$ on EOD rate in G. sylvius, providing the first insights into the effects of $\mathrm{MeHg}$ on EODs in a weak electric fish.

\section{Materials and Methods Subjects}

The experimental conditions and procedures were approved by the Research Ethics Committee of
Universidade Estadual Paulista (UNESP) at the $12^{\text {th }}$ Ordinary Meeting. Gymnotus fish, with an average weight of $29.7 \pm 11.6 \mathrm{~g}$ and length of $15 \pm 7 \mathrm{~cm}$, were collected from the Tietê River, São Paulo state, Brazil. The fish were maintained under controlled laboratory conditions and kept individually in glass aquaria $(.6 \times$ $.25 \times .4 \mathrm{~m})$ with hiding locations made of polyvinyl chloride tubes. The photoperiod (14 h light, $10 \mathrm{~h}$ dark), water temperature $\left(23 \pm 3^{\circ} \mathrm{C}\right), \mathrm{pH}(7.3 \pm .5)$, and aeration $\left(5 \pm .5 \mathrm{mg}\right.$ dissolved $\left.\mathrm{O}_{2}\right)$ were controlled. Animals were fed daily with earthworms (Lumbricus sp.).

Cytogenetic analysis was conducted for species confirmation. The mitosis stimulation protocol was adapted to fish (Cole \& Leavens, 1971; Oliveira, Almeida-Toledo, Foresti, \& Toledo-Filho, 1988), and the mitotic chromosome preparation was described previously (Foresti, Oliveira, \& Almeida-Toledo, 1993). The fish were anesthetized in an ice bath and sacrificed by transecting the spinal cord. All animals presented the $2 \mathrm{n}=40$ karyotype belonging to the species G. sylvius.

\section{Apparatus}

The EOD recordings were conducted in the Electric Engineering Laboratory (UNESP, Bauru). The animals were transferred to the laboratory on the days of data collection and individually kept in an aquarium $(.3 \times .14$ $\times .2 \mathrm{~m}$ ) with a polyvinyl chloride tube and placed inside a wire-mesh Faraday cage. The EODs were detected by two electrodes made of $50-\Omega$ impedance coaxial cables attached to the opposite ends of the hiding tube. A Tektronix digital oscilloscope (TDS2014) collected the signals from the electrodes and produced discharge rate curves that were stored on a computer. The EOD rates were obtained for each animal with minute-by-minute sampling for 30 continuous minutes per day. Therefore, 30 recordings were collected per fish per day.

\section{Drug}

$\mathrm{MeHg}$ chloride $\left(\mathrm{CH}_{3} \mathrm{HgCl}_{2}\right)$ was purchased from Sigma-Aldrich (Saint-Quentin Fallavier, France). After the experiments, the contaminated material was acidified $(\mathrm{pH}<2)$, neutralized in amide, and discarded for incineration.

\section{Procedure}

The chronic and acute effects of ingested $\mathrm{MeHg}$ chloride on EOD rate were investigated. The fish were exposed to $\mathrm{MeHg}$ through the ingestion of contaminated earthworms. The earthworms were injected with $\mathrm{MeHg}$ using insulin syringes at the time the fish were fed. Oral exposure to $\mathrm{MeHg}$ has important environmental significance because it is similar to the most common human exposure and avoids the discomfort of injections (Farina et al., 2011) and handling stress.

To evaluate the cumulative effects of $\mathrm{MeHg}$ administration over 18 days (day 19 until day 36), five fish $(29.3 \pm 9.0 \mathrm{~g}, 15.3 \pm 2 \mathrm{~cm})$ were subjected to multiple doses of $\mathrm{MeHg}$ (chronic treatment). They were 
exposed to MeHg every 2 days for 18 days, with a total of nine dietary exposures to $\mathrm{MeHg}$. With each exposure, the fish were exposed to $4 \mu \mathrm{g} / \mathrm{kg} \mathrm{MeHg}$.

To evaluate the effect of methylmercury depuration over 18 days (day 19 until day 36), five fish $(24.6 \pm 13$ $\mathrm{g}, 14.8 \pm 2.5 \mathrm{~cm})$ were subjected to a single dose of $\mathrm{MeHg}$ (acute treatment). They were exposed to $20 \mu \mathrm{g} /$ $\mathrm{kg} \mathrm{MeHg.}$

Because all of the fish served as their own controls, the control data for both treatments were collected before dietary $\mathrm{MeHg}$ exposure. The control data for both treatments were collected every 2 days for 18 days (day 1 until day 18), with a total of nine sessions. In each session, the EOD recordings began immediately after a 5-min habituation period.

After the control EOD recordings, the fish were subjected to the acute and chronic experiments. The acutely treated animals were subjected to nine sessions of EOD recordings after $\mathrm{MeHg}$ administration, repeating the baseline protocol of the control sessions. The same occurred with the chronically treated animals, but the recordings were made on the interim days between dietary $\mathrm{MeHg}$ administration.

\section{Statistical analysis}

The 30 EOD rate measurements collected for each fish per day were averaged into one measure. The individual mean EOD rate was analyzed by comparing the data before and after $\mathrm{MeHg}$ administration for each treatment regimen. Each animal had its EOD rate recorded repeatedly after or during the treatments. Data were analyzed by one-way repeated-measures analysis of variance (ANOVA). The significance level was 95\% $(p<.05)$.

\section{Results}

\section{Chronic MeHg treatment}

The one-way repeated-measures ANOVA indicated that chronic $\mathrm{MeHg}$ treatment altered the EOD rate in $G$. sylvius $(F=5.01, d f=17, p<.001)$. The EOD rate exhibited oscillations during treatment (Figure 1). According to the Tukey post hoc test, the EOD rate significantly increased during the last three recordings (day 32 until day 36) when the estimated cumulative dose reached $36 \mu \mathrm{g} / \mathrm{kg}$.

\section{Acute MeHg treatment}

One-way repeated-measures ANOVA indicated that acute $\mathrm{MeHg}$ treatment increased the EOD rate in G. sylvius $(F=3.63, d f=17, p<.001)$. From day 26 to day 30 , the EOD rate significantly increased compared with the control recordings (Tukey test; $p<.05$; Figure 2 ). The prominent increase in EOD occurred on day 28 (Tukey test, $p<.05$ ).

\section{Discussion}

The effects of dietary $\mathrm{MeHg}$ administration were investigated on EOD rate in the weak electric fish $G$. sylvius using two treatment regimens. The chronic treatment was conducted to evaluate the consequences of small but constant exposure to $\mathrm{MeHg}$, simulating trophic accumulation. The acute treatment was

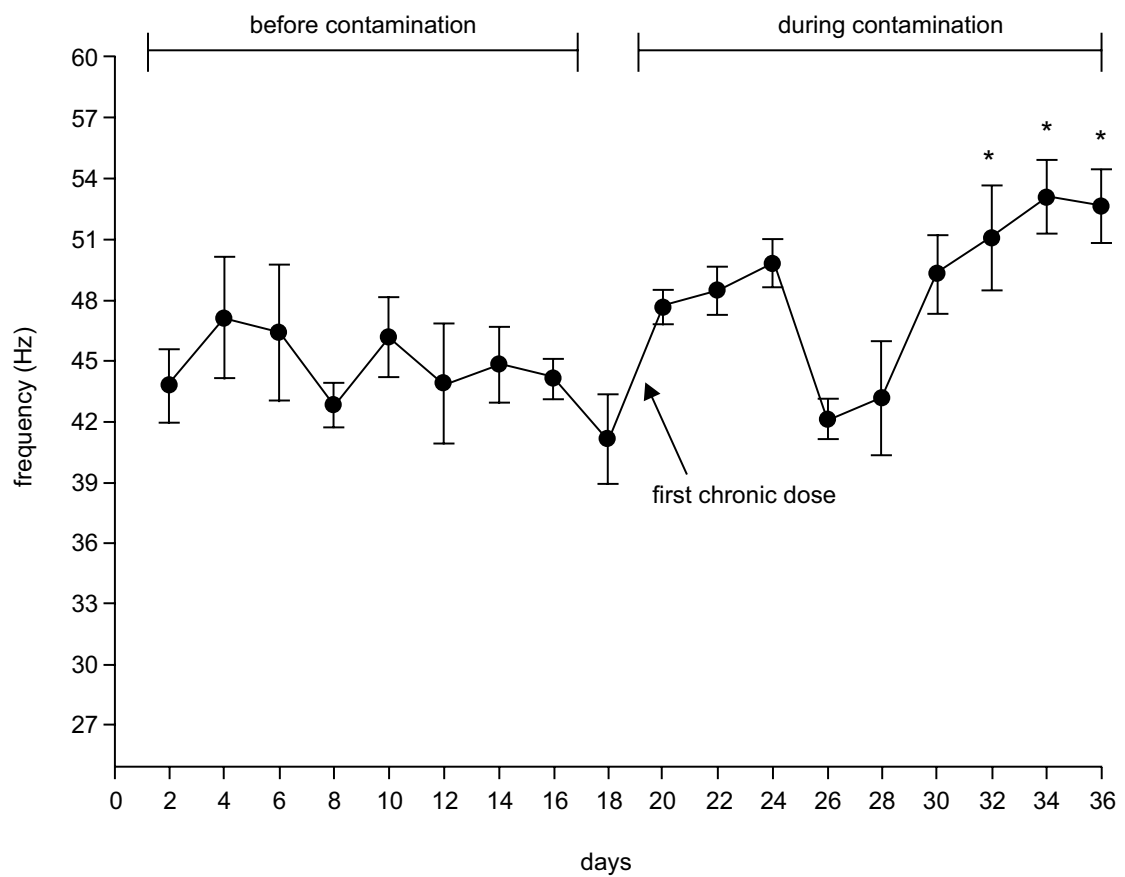

Figure 1. Mean electric organ discharge (EOD) rates $( \pm \mathrm{SEM})$ in Gymnotus sylvius with chronic MeHg treatment. The control data were collected on the interim days for 18 days before $\mathrm{MeHg}$ administration (day 1 until day 18). The fish were then subjected to multiple doses of MeHg. They were exposed to MeHg every 2 days for 18 days, with a total of nine dietary exposures to $\mathrm{MeHg}$ (day 19 until day 36). In each exposure the fish received $4 \mu \mathrm{g} / \mathrm{kg} \mathrm{MeHg}$. The recordings were made on the interim days between dietary MeHg exposures. ${ }^{*} p<.05$, different from control recordings. 


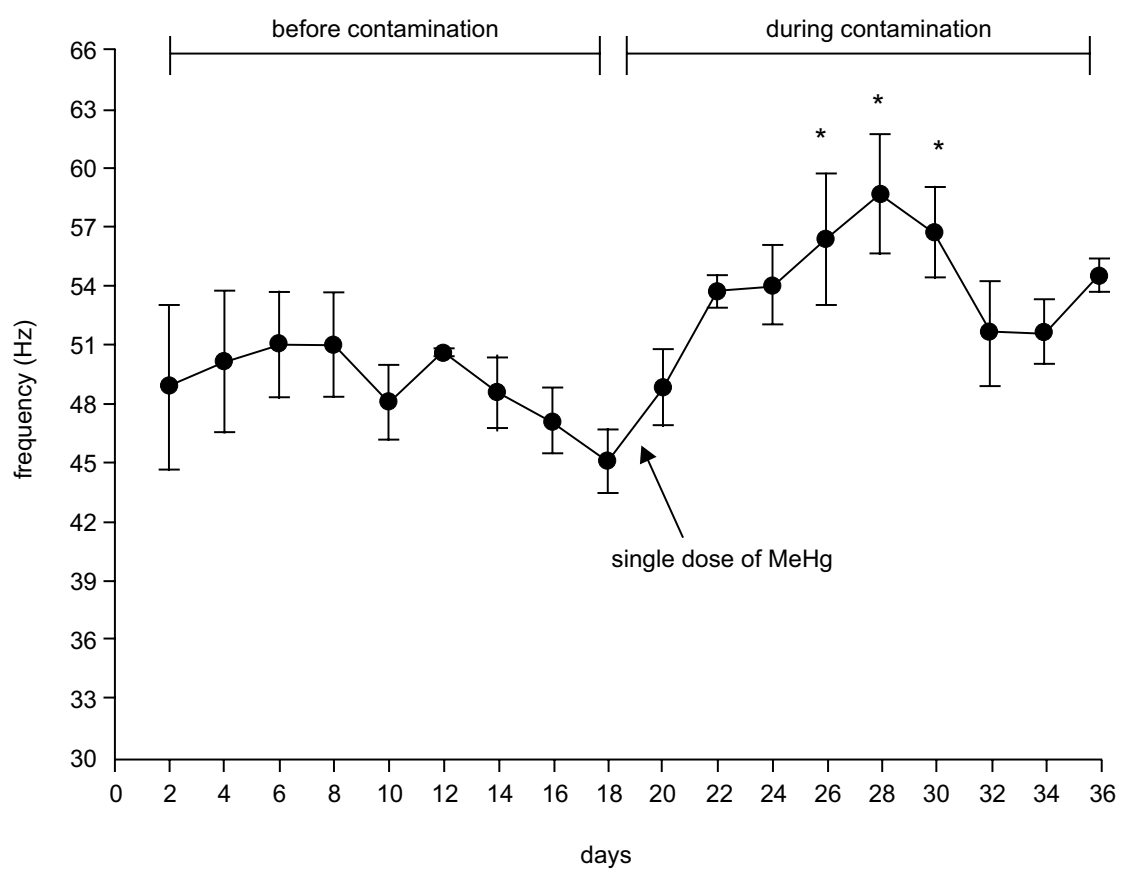

Figure 2. Mean EOD rates $( \pm \mathrm{SEM})$ in G. sylvius with acute MeHg treatment. The control data were collected on the interim days for 18 days before $\mathrm{MeHg}$ administration (day 1 until day 18). The fish were then subjected to a single dose of $20 \mu \mathrm{g} / \mathrm{kg} \mathrm{MeHg}$. The EOD recordings were collected for nine sessions (day 19 until day 36 ) by repeating the baseline protocol for controls. ${ }^{*} p<.05$, different from control recordings.

conducted to evaluate the effects of an elevated dose of $\mathrm{MeHg}$ and post-depuration events. In both treatments, $\mathrm{MeHg}$ altered the modulation of EOD, leading to an evident increase in the discharge rate of electric pulses.

Chronic $\mathrm{MeHg}$ treatment increased the EOD rate in G. sylvius, especially during the final stages of treatment. The progressively increasing pattern may be attributable to dose-dependent $\mathrm{MeHg}$ accumulation. The sequential doses of $\mathrm{MeHg}$ at short time intervals can accumulate in the organism (Oliveira-Ribeiro, Belger, Pelletier, \& Rouleau, 2002) because of biomagnification caused by the high assimilation and low elimination rate of $\mathrm{MeHg}$ in fish (Wang et al., 2010; Dutton \& Fischer, 2011). Horizontal cells in the retina in Hoplias malabaricus also presented increased responsiveness as a consequence of low-dose MeHg exposure (Tanan et al., 2006).

The acute treatment indicated that the $\mathrm{MeHg}$ depuration period affected the modulation of electric pulses in G. sylvius. Although the $\mathrm{MeHg}$ concentration was not quantified in G. sylvius tissues, it likely reached the brain of the fish, leading to alterations in the neural control of the EOD rate. $\mathrm{MeHg}$ is totally retained in several fish species, including 7 days after depuration in Oreochromis niloticus (Wang et al., 2010), 9 days after feeding on worms contaminated with MeHg in Fundulus heteroclitus (Dutton \& Fischer, 2011), and 15 days after depuration in Salmo gairdneri (Hawryshyn \& Mackay, 1979). MeHg can accumulate in the brain in S. gairdneri (Hawryshyn \& Mackay, 1979) and gills, viscera, skin, liver, brain, and muscle in Fundulus heteroclitus, which presents the highest concentration of $\mathrm{MeHg}$ after 9 days of dietary exposure (Dutton \& Fischer, 2011).

The increase in the EOD rate observed with both treatments in the present study can be related to
MeHg neurotoxicity that occurs through an excitotoxic mechanism. Electric organ discharges are modulated by a series of neural nuclei including the electrosensorius nucleus, diencephalic pre-pacemaker nucleus, and bulbar pacemaker nucleus in the brain as described in $G$. carapo (Correa \& Hoffman, 1999). This circuit possesses $\gamma$-aminobutyric acid (GABAergic) and glutamatergic projections in which the respective neurotransmitters interact with $\mathrm{GABA}_{\mathrm{A}}$ and NMDA receptors. Glutamate increases the EOD rate, and GABA reduces the EOD rate in the gymnotiform electric fish Hypopomus brevirostris (Kawasaki \& Heiligenberg, 1990). MeHg neurotoxicity is related to glutamate dyshomeostasis in the CNS, which provokes extracellular glutamate accumulation in astrocytes. This phenomenon occurs by inhibiting astrocytic glutamate uptake and increasing glutamate release (Allen et al., 2002; Aschner et al., 2000; Farina et al., 2011). If $\mathrm{MeHg}$ mediates excitotoxicity via accumulation of extracellular glutamate levels, then the increase in EOD rate in G. sylvius may be a consequence of MeHg-induced excitotoxicity. The fine-tuning of the EOD rate is crucial for electrical communication among Gymnotus species, which determines reproductive and non-reproductive interactions and affects social and ecological aspects (Gouvêa Junior, Stopa, Paula, \& Hoshino, 2002).

In summary, dietary $\mathrm{MeHg}$ administration affected the EOD in the weak electric fish G. sylvius, inducing a significant dose- and depuration-dependent increase in the EOD rate. Future investigations are needed to elucidate the effects of $\mathrm{MeHg}$ on glutamate homeostasis in the brain in G. sylvius and the direct effects of $\mathrm{MeHg}$ on the electric organ in the fish. The present study points to the EOD rate as novel response of fish to $\mathrm{MeHg}$ 
administration. Measuring EODs is inexpensive, useful, and non-invasive and may be used to monitor mercurial contamination in water and animals, especially in Amazonian rivers.

\section{Acknowledgements}

The authors are grateful to FAPESP (São Paulo Research Foundation, Process no. 04/14160-0) and CNPq (National Council for Scientific and Technological Development, Process no. 402817/2004-4). We also thank Helton Gonzales and Nelson Medeiros for technical assistance and Prof. Dr. Fábio Foresti and Diogo Teruo Hashimoto for assistance with the cytogenetic analysis.

\section{References}

Akagi, H., Malm, O., Kinjo, Y., Harada, M., Branches, F. J. P., Pfeiffer, W. C., \& Kato, H. (1995). Methylmercury pollution in the Amazon, Brazil. Science of the Total Environment, 175, 85-95.

Allen, J. W., Shanker, G., Tan, K. H., \& Aschner, M. (2002). The consequences of methylmercury exposure on interactive functions between astrocytes and neurons. Neurotoxicology, 23, 755-759.

Aschner, M., Yao, C. P., Allen, J. W., \& Tan, K. H. (2000). Methylmercury alters glutamate transport in astrocytes. Neurochemistry International, 37, 199-206.

Baatrup, E. (1991). Structural and functional effects of heavy metals on the nervous system, including sense organs, of fish. Comparative Biochemistry and Physiology Part C: Comparative Pharmacology, 100, 253-257.

Bondy, S. C., \& Agrawal, A. K. (1980). The inhibition of cerebral high affinity receptor sites by lead and mercury compounds. Archives of Toxicology, 46, 249-256.

Castoldi, A. F., Coccini, T., Ceccatelli, S., \& Manzo, L. (2001). Neurotoxicity and molecular effects of methylmercury. Brain Research Bulletin, 55, 197-203.

Cole, C. J., \& Leavens, C. R. (1971). Chromosome preparations of amphibians and reptiles: Improved technique. Herpetological Review, 3, 102.

Correa, S. A. L., \& Hoffmann, A. (1999). Effects of season and arousal state on the novelty response in Gymnotus carapo. In A. L. Val, \& V. M. F. Almeida e Val (Eds.), Biology of tropical fishes (pp. 149160). Manaus: INPA.

Dutton, J., \& Fischer, N. S. (2011). Bioaccumulation of As, Cd, Cr, Hg (II), and MeHg in killfish (Fundulus heteroclitus) from amphipod and worm prey. Science of the Total Enviromment, 409, 3438-3447.

Farina, M., Rocha, J. B. T., \& Aschner, M. (2011). Mechanisms of methylmercury-induced neurotoxicity: Evidence from experimental studies. Life Sciences, 89, 555-563.

Foresti, F., Oliveira, C., \& Almeida-Toledo, L. F. (1993). A method for chromosome preparations from large fish specimens using in vitro short-term treatment with colchicine. Experientia, 49, 810-813.

Gouvêa Junior, F., Stopa, R. M., Paula, H. M. G., \& Hoshino, K. (2002). Suspensão das descargas de eletrolocação-comunicação e tamanho corporal no peixe-elétrico Gymnotus carapo Miller, 1966 (Osteichtyes, Gymnotidae). Revista Brasileira de Zoociências, 4, 203-214.

Grotto, D., Valentini, J., Serpeloni, J. M., Monteiro, P. A. P., Latorraca, E. F., de Oliveira, R. S., ... Barbosa, F., Jr. (2011). Evaluation of toxic effects of a diet containing fish contaminated with methylmercury in rats mimicking the exposure in the Amazon riverside population. Environmental Research, 111, 1074-1082.
Hammerschmidt, C. R., Sandheinrich, M. B., Wiener, J. G., \& Rada, R. G. (2002). Effects of dietary methylmercury on reproduction of fathead minnows. Environmental Science and Technology, 36, 877-883.

Hawryshyn, C. W., \& Mackay, W. C. (1979). Toxicity and tissue uptake of methylmercury administered intraperitoneally to rainbow trout (Salmo gairdneri Richardson). Bulletin of Environmental Contamination and Toxicology, 23, 79-86.

Hopkins, C. D. (1988). Neuroethology of electric communication. Annual Review of Neuroscience, 11, 497-535.

Kawasaki M., \& Heiligenberg W. (1990). Different classes of glutamate receptors and GABA mediate distinct modulations of a neuronal oscillator, the medullary pacemaker of a gymnotiform electric fish. Journal of Neuroscience, 10, 3896-3904.

Mieiro, C. L., Pereira, M. E., Duarte, A. C., \& Pacheco, M. (2011). Brain is a critical target in environmentally exposed fish (Dicentrarchus labrax): Bioaccumulation and oxidative stress profiles. Aquatic Toxicology, 103, 233-240.

Oliveira, C., Almeida-Toledo, L. F., Foresti, F., \& Toledo-Filho, S. A. (1988). Supernumerary chromosomes, Robertsonian rearrangements and multiple NORs in Corydoras aeneus (Pisces, Siluriformes, Callichthyidae). Caryologia, 41, 227-236.

Oliveira-Ribeiro, C. A., Belger, L., Pelletier, E., \& Rouleau, C. (2002). Histopathological evidence of inorganic mercury and methyl mercury toxicity in the arctic charr (Salvelinus alpinus). Environmental Research, 90, 217-225.

Pinheiro, M. C. M., Guimarães, G. A., Nakanishi, J., Oikawa, T., Vieira, J. L., Quaresma, M., Cardoso, B., \& Amoras, W. (2000). Total mercury in hair samples of inhabitants of Tapajós River, Pará State, Brazil. Revista da Sociedade Brasileira de Medicina Tropical, 33, 181-184.

Rabitto, I. S., Bastos, W. R., Almeida, R., Anjos, A., Holanda, I. B. B., Galvão, R. C. F., ... Ribeiro, C. A. O. (2011). Mercury and DDT exposure risk to fish-eating human populations in Amazon. Environment International, 37, 56-65.

Smith, G. M., \& Weis, J. S. (1997). Predator-prey relationships in mummichogs (Fundulus heteroclitus (L.)): Effects of living in a polluted environment. Journal of Experimental Marine Biology and Ecology, 209, 75-87.

Stopa, R. M., \& Hoshino, K. (1999). Electrolocation-communication discharges of the fish Gymnotus carapo L. (Gymnotidae: Gymnotiformes) during behavioral sleep. Brazilian Journal of Medical and Biological Research, 32, 1223-1228.

Tanan, C. L., Ventura, D. F., Souza, J. M., Grotzner, S. R., Mela, M., Gouveia, A., Jr., \& Oliveira-Ribeiro, C. A. (2006). Effects of mercury intoxication on the response of horizontal cells of the retina of thraira fish (Hoplias malabaricus). Brazilian Journal of Medical and Biological Research, 39, 987-995.

Tsai, C. L., Jang, T. H., \& Wang, L. H. (1995). Effects of mercury on serotonin concentration in the brain of tilapia, Oreochromis mossambicus. Neuroscience Letters, 184, 208-211.

Vicari, T., Ferraro, M. V. M., Ramsdorf, W. A., Mela, M., Ribeiro, C. A. O., \& Cestari, M. M. (2012). Genotoxic evaluation of different doses of methylmercury $\left(\mathrm{CH}_{3} \mathrm{Hg}^{+}\right)$in Hoplias malabaricus. Ecotoxicology and Environmental Safety, 82, 47-55.

Vilagi, I., Doczi, J., \& Banczerowski-Pelyhe, I. (2000). Altered electrophysiological characteristics of developing rat cortical neurones after chronic methylmercury chloride treatment. International Journal of Developmental Neuroscience, 18, 493-499.

Wang, R., Wong, M. H., \& Wang, W. X. (2010). Mercury exposure in the freshwater tilapia Oreochromis niloticus. Environmental Pollution, 158, 2694-2701.

Webber, H. M., \& Haines, T. A. (2003). Mercury effects on predator avoidance behavior of a forage fish, golden shiner (Notemigonus crysoteucas). Enviromental Toxicology and Chemistry, 22, $1556-1561$ 
